\title{
Effective treatment for prevention of post-operative adhesion after strabismus surgery in experimental rabbit model: $0.5 \%$ tranilast ophthalmic solution
}

\author{
Sang Uk Choi, Kyoung Woo Kim and Nam Ju Moon ${ }^{*}$
}

\begin{abstract}
Background: Postoperative adhesion is one of the major complications of strabismus surgery and result in motility dysfunction that brings unpredictable surgical outcomes. However, there was no definitely accepted treatment method to prevent postoperative adhesion.

Methods: A prospective, randomized, controlled experimental animal study was performed. Both eyes of each of 14 New Zealand White rabbits underwent superior rectus muscle recession. After the surgical procedure, the subjects were divided randomly into two groups; $0.5 \%$ tranilast ophthalmic solutions and fluoroquinolone antibiotic eye drops were administered to the group tranilast $(N=14)$, while the group control $(N=14)$ received fluoroquinolone eye drops only. Five weeks after surgery, we evaluated gross adhesions with a numeric score (0 to 4). In addition, histopathologic examination with hematoxylin \& eosin staining, Masson's-trichrome staining, and anti-transforming growth factor beta 1 (TGF- $\beta 1$ ) immuno-histochemical staining were done.

Results: The group tranilast showed significantly less gross adhesion and inflammation than the group control ( $P=0.01$ and $P<0.001$, respectively). Masson's-trichrome staining revealed that post-operative collagen deposition was more prominent in the group control than the group tranilast $(P<0.001)$. Moreover, remarkable TGF- $\beta 1$ expression was observed in areas with excessive collagen deposition.
\end{abstract}

Conclusions: Instillation of $0.5 \%$ tranilast ophthalmic solution is a simple and effective method for preventing post-operative adhesion after strabismus surgery.

Keywords: Tranilast, Strabismus surgery, Adhesion

\section{Background}

Postoperative adhesion is one of the major complications of strabismus surgery and result in motility dysfunction that brings unpredictable surgical outcomes $[1,2]$. Alleviating inflammation and thereby inhibiting the overproduction of extracellular matrix is essential to prevent fibrovascular proliferation and scar formation $[3,4]$. Therefore, various surgical and medical approaches have been used to reduce postoperative inflammation and adhesion after strabismus surgery.

\footnotetext{
* Correspondence: njmoon@chol.com

Department of Ophthalmology, College of Medicine, Chung-Ang University
} Hospital, 102, Heukseok-ro, Dongjak-gu, Seoul 06973, Republic of Korea
These include antimetabolites (5-fluorouracil, mitomycin C), mechanical barriers (silicone sleeve, polyglactin 910 mesh, Seprafilm [Genzyme, Cambridge, MA, USA]), anti-inflammatory agents (triamcinolone), and lubricants (sodium hyaluronate) [1, 2, 5-10]. None of these, however, has been generally accepted because of associated complications, limitations or inconsistent outcomes [4].

Tranilast is a derivative of the amino acid tryptophan and was developed as an anti-allergy drug [11, 12]. It also prevents inflammation and collagen synthesis derived from keloid and hypertrophic scarring [11]. In addition, several in vitro and in vivo studies revealed that tranilast directly affected various parenchymal cells as anti-inflammatory and anti-fibrotic agent. Tranilast 
significantly reduced collagen synthesis, chemotaxis, cell migration, transforming growth factor beta 1 (TGF- $\beta 1$ ) secretion, matrix metalloproteinase- 1 secretion, and extracellular matrix production in various parenchymal cells [13-18].

In the ophthalmic field, tranilast eye drops are used to treat fibrotic ophthalmic diseases such as symblepharon, pterygium, and corneal haze after photorefractive keratectomy [19-21]. Prior study has demonstrated that direct slow-releasing tranilast could reduce adhesion and allowed delayed adjustment after surgery [22]. However, that is not a simple method to use in usual clinical setting. And, a long-term effect and safety of direct releasing system was not established in the wound healing. Also direct exposure of tranilast could induce stromal cell apoptosis [23].

With these backgrounds, the purpose of this study was to evaluate the anti-fibrotic effect of tranilast eye drops on experimental strabismus surgery in rabbit model, as measured by gross adhesion grading and histopathologic evaluation.

\section{Methods}

A prospective, masked observer, controlled experiment was performed on adult female 14 New Zealand White rabbits (DooYeol Biotech, Seoul, Korea) weighing 2.0 to $3.0 \mathrm{~kg}$. which housed in alone of given 2 weeks to acclimate to the housing facility. The rabbits were housed in individual mesh cages $(0.90 \times 0.65 \times 0.50 \mathrm{~m})$ hung at a height of $0.8 \mathrm{~cm}$ from the collecting trays and given access to rat maintenance food (Laboratory Rabbit Diet 5321, LabDiet, St. Louis, MO, USA) and water ad libitum. Environmental conditions were a temperature of $22{ }^{\circ} \mathrm{C} \pm 2^{\circ}$, humidity of $50 \% \pm 10 \%$, lighting of $360 \mathrm{~lx}$ and a $12: 12 \mathrm{~h}$ light:dark cycle with lights on at $6: 30 \mathrm{am}$ and off at 6:30 pm. All experiments were conducted in accordance with the ARRIVE Guidelines for reporting animal research. And, study protocol was approved by Chung-Ang university institutional animal care and use committee (number 14-0043).

\section{Surgical procedure}

We performed standard 3-mm recession with preserving Tenon's capsule of the superior rectus muscle (SRM) strabismus surgery on both eyes in all rabbits. All surgeries were performed by the same surgeon (NJM). The animals were anesthetized with an intramuscular injection containing a mixture of tiletamine and zolazepam (Zoletil ${ }^{\circ}$, Virbac Lab, France) at $12.5 \mathrm{mg} / \mathrm{kg}$, an aqueous solution of $2 \%$ xylazine (Rompun ${ }^{\circ}$, Bayer Korea, Seoul, Korea) at $12.5 \mathrm{mg} / \mathrm{kg}$, and topical anesthesia with $0.5 \%$ proparacaine hydrochloride eye drops (Alcaine ${ }^{\circ}$, Alcon, Fort Worth, TX, USA). A $5 \%$ povidone-iodine solution was applied to the inferior and superior fornix before surgery for antisepsis. The SRM was exposed through a limbal incision and was then isolated on a muscle hook. Three-millimeter recession was conducted with a double-armed 7-0 polyglactin suture (Vicryl ${ }^{\circ}$, Ethicon, Piscataway, NY, USA). The conjunctiva was then repositioned carefully and closed with two 7-0 polyglactin sutures in all eyes. Postoperatively, an antibiotic eye drop (Cravit ${ }^{\circ}$, Santen, Osaka, Japan) was used three times a day in one eye $(N=14)$ and an antibiotic eye drop and $0.5 \%$ tranilast eye drops (Krix ${ }^{\circ}$, Choongwae Shin Yak, Seoul, Korea) were used three times a day in the contralateral eye $(N=14)$ which was randomly selected by using table of random numbers. All eye drops were administered 6:30 to 7:00, 12:30 to $13: 00$, and 18:30 to 19:00.

\section{Evaluation of gross adhesions}

Five weeks after the surgery all rabbits were reanesthetized. Then, gross adhesion grades of recession site were evaluated. The grades were classified by severity and were scored from 0 to 4 as follows: $0=$ no adhesion; $1=$ filmy adhesion easily separable with blunt dissection; 2 =mild-to-moderate adhesion with freely dissectible plane; $3=$ moderate-to-dense adhesion with difficult dissection; and $4=$ non-dissectible plane (Fig. 1).

\section{Histopathological examination}

After adhesion grading, the eyes were enucleated beware of damage to the recession site. A two of $4 \mathrm{~mm}$ width incision was made parallel with recession at $2 \mathrm{~mm}$ anteriorly and $4 \mathrm{~mm}$ posteriorly to recession site. Then incision was extended to first two incisions to make

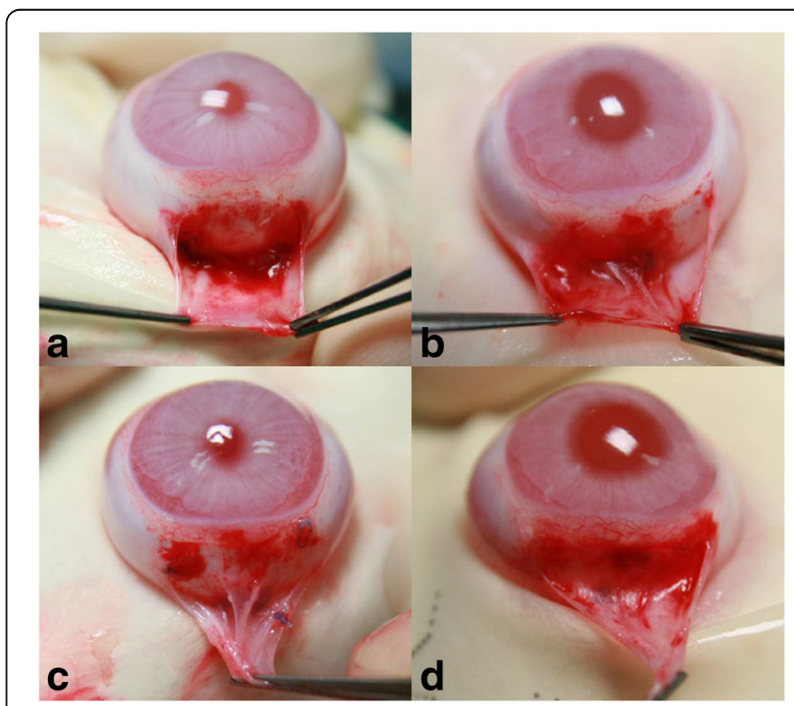

Fig. 1 Reference photograph of the degree of adhesion. a Grade 1, filmy adhesion easily separable with blunt dissection; b grade 2 , mild-to-moderate adhesion with a freely dissectible plane; c grade 3 , moderate-to-dense adhesion with difficult dissection; $\mathbf{d}$ grade 4 , non-dissectible plane 
Table 1 Numerical gross adhesion grades for each eye

\begin{tabular}{lllllll}
\hline Adhesion grade & 0 & 1 & 2 & 3 & 4 & Total N (\%) \\
\hline Control & $0(0 \%)$ & $0(0 \%)$ & $4(29 \%)$ & $8(57 \%)$ & $2(14 \%)$ & $14(100 \%)$ \\
Tranilast & $0(0 \%)$ & $6(43 \%)$ & $7(50 \%)$ & $1(7 \%)$ & $0(0 \%)$ & $14(100 \%)$
\end{tabular}

histologic block. The histologic block fixed in $10 \%$ formaldehyde and embedded in paraffin. Three sagittal sections for each block were made perpendicularly to the line of the postsurgical insertion of the SRM. Tissues in each group were examined microscopically using hematoxylin \& eosin (H\&E) staining to general histologic observation. Inflammation was quantified by averaging the number of inflammatory cells in three high powered field views on light microscopy of recession site stroma on each section. Masson's-trichrome staining was performed to quantification of collagen formation, and TGF- $\beta 1$ expression was identified using antiTGF- $\beta 1$ antibody (Goat anti-Rabbit IgG Antibody; Novusbio, Littleton, CO, USA) through immunohistochemical (IHC) staining.

\section{Quantification of fibrosis}

Three sections of Masson's-trichrome staining images of extraocular muscle at recession site (original magnification $\times 200$ ), were obtained per each eye using the CCD camera, light microscope, and computer software (Zeiss AxioCam ICc1, Zeiss Axiskop40 microscope, and ZEN 2012 software, Zeiss Korea, Seoul, Korea). Then, the obtained images were imported into Adobe ${ }^{\circ}$ Photoshop ${ }^{\circ}$ CS5 software (Adobe Systems Inc, San Jose, CA, USA). Total pixel numbers of intermuscular collagen deposition of each section were recorded using polygonal lasso tool according to the previously published protocol to quantify the degree of fibrosis [24].

\section{Statistical analyses}

Fisher's exact test was used to determine the relationship between the severity of adhesion (Grade 0 to 4 ) and the application of tranilast eye drops. The Mann-Whitney test was used to compare degree of inflammation on $\mathrm{H} \& \mathrm{E}$ staining and amount of fibrosis on Masson'strichrome staining. Statistical analyses were performed with SPSS version 18.0 (SPSS, Inc., Chicago, IL, USA)

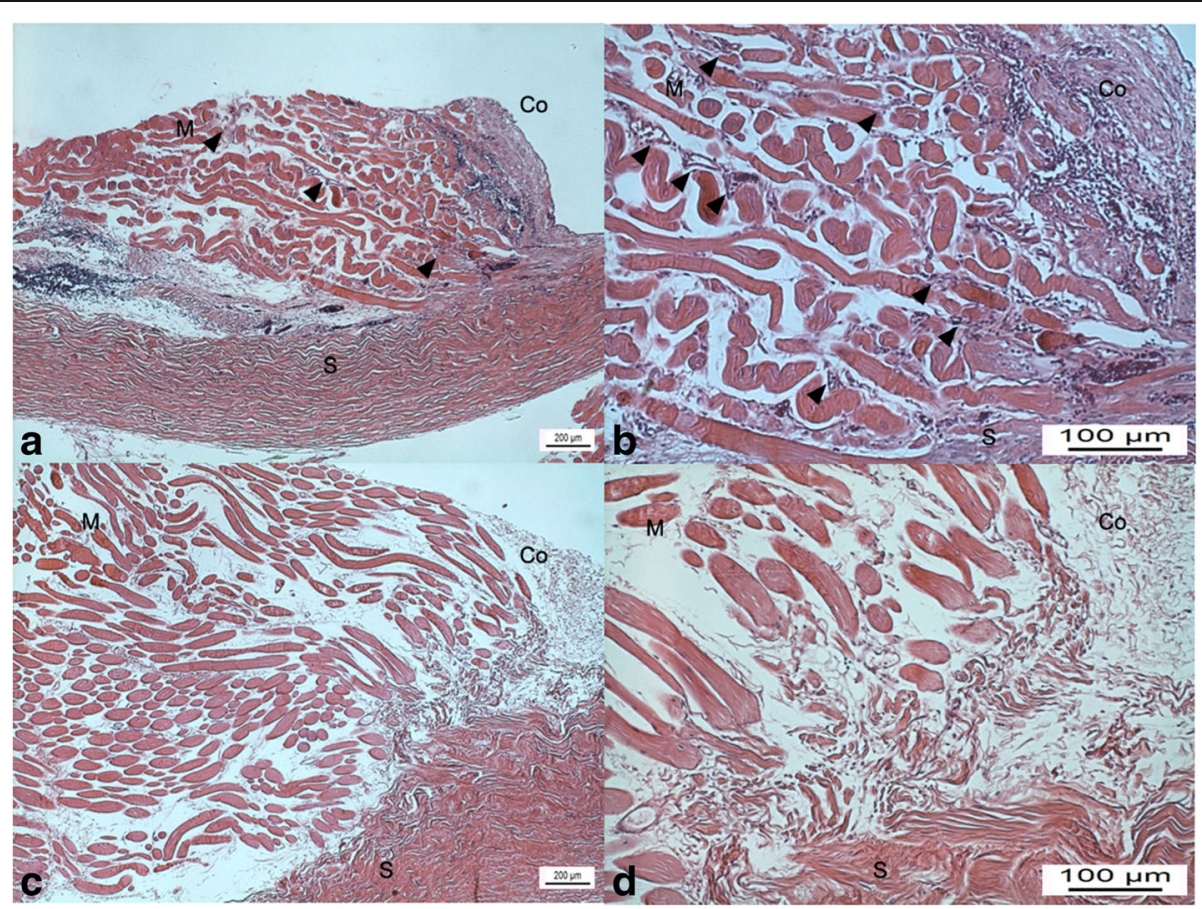

Fig. 2 Light microscopic findings on hematoxylin and eosin staining of group control $(\mathbf{a}, \mathbf{b})$ and group tranilast (c, $\mathbf{d})$. The group control shows more prominent fibrovascular proliferation in superior rectus muscle then the group tranilast (arrow heads in [a, $\mathbf{b}]$ ). The group tranilast shows scant fibrosis and inflammatory cell infiltration ( $\mathbf{c}$, d; left column, original magnification $\times 40$; right column, original magnification $\times 100$; $M$ superior rectus muscle, S sclera, Co Conjunctiva) 
Table 2 Inflammatory cell count per high power field on light microscopy

\begin{tabular}{lcc}
\hline & Cells/HPF (mean \pm SD) & \\
\hline Control & $43.35 \pm 12.25$ & $P<0.001^{*}$ \\
Tranilast & $23.35 \pm 10.55$ & \\
\hline
\end{tabular}

HPF high power field, SD standards deviation

*Mann-Whitney test

software. The level of statistical significance was set at $5 \%(P<0.05)$ for all tests.

\section{Results}

\section{Degree of gross adhesion}

Eyes in group tranilast (14/28 eyes) showed filmy adhesion (score 1; 6 eyes) or mild-to-moderate adhesion (score 2; 7 eyes) except one which had moderate-todense adhesion (score 3) (Table 1). Whereas, the eyes in group control (14/28 eyes) revealed adhesion ranging from mild-to-moderate (score $2 ; 4$ eyes) and moderateto-dense (score 3; 8 eyes) to non-dissectible (score 4; 2 eyes). There was less post-operative recession site adhesion in group tranilast compared to group control $(P=0.01$, Fisher's exact test). There was no adverse event such as infection in the experimental and control groups.

\section{Histopathologic examination and quantitative analysis}

The group tranilast demonstrated less inflammation and fibrosis around the SRM than group control (Fig. 2).
The group control presented significantly more inflammatory cells (mostly small lymphocytes) than the group tranilast (Table 2; $P<0.001$, Mann-Whitney test). Masson's trichrome staining revealed that group control presented more intense post-operative fibrosis than group tranilast (Fig. 3). Moreover, in quantitative analysis of fibrosis, there was a significant reduction of muscle fibrosis in the tranilast treated eyes compared with control eyes (Table 3; $P<0.001$, Mann-Whitney test). The group control showed more prominent TGF- $\beta 1$ expression than group tranilast (Fig. 4).

\section{Discussion}

Several studies were performed to prevent formation of adhesion and to alleviate motility dysfunction after strabismus surgery by using various materials and medical agents. The materials which include tissue implants such as amniotic membrane, silicone, supramid sleeve, polyglactin mesh sleeves $[4,25,26]$. However, various level of clinical success and foreign body reaction or extrusion has discouraging the purpose of their insertion [1]. Similarly, the medical agent such as mitomycin $\mathrm{C}$, and 5 -fluorouracil demonstrated positive results in reducing the postoperative adhesions and fibrosis [1, 7]. However, these agents have the risk for serious side effects such as corneoscleral melt [27]. More recently, monoclonal antivascular endothelial growth factor antibody has been investigated to reduce postoperative adhesions. But, it was insufficient to prevent postoperative adhesions [28].

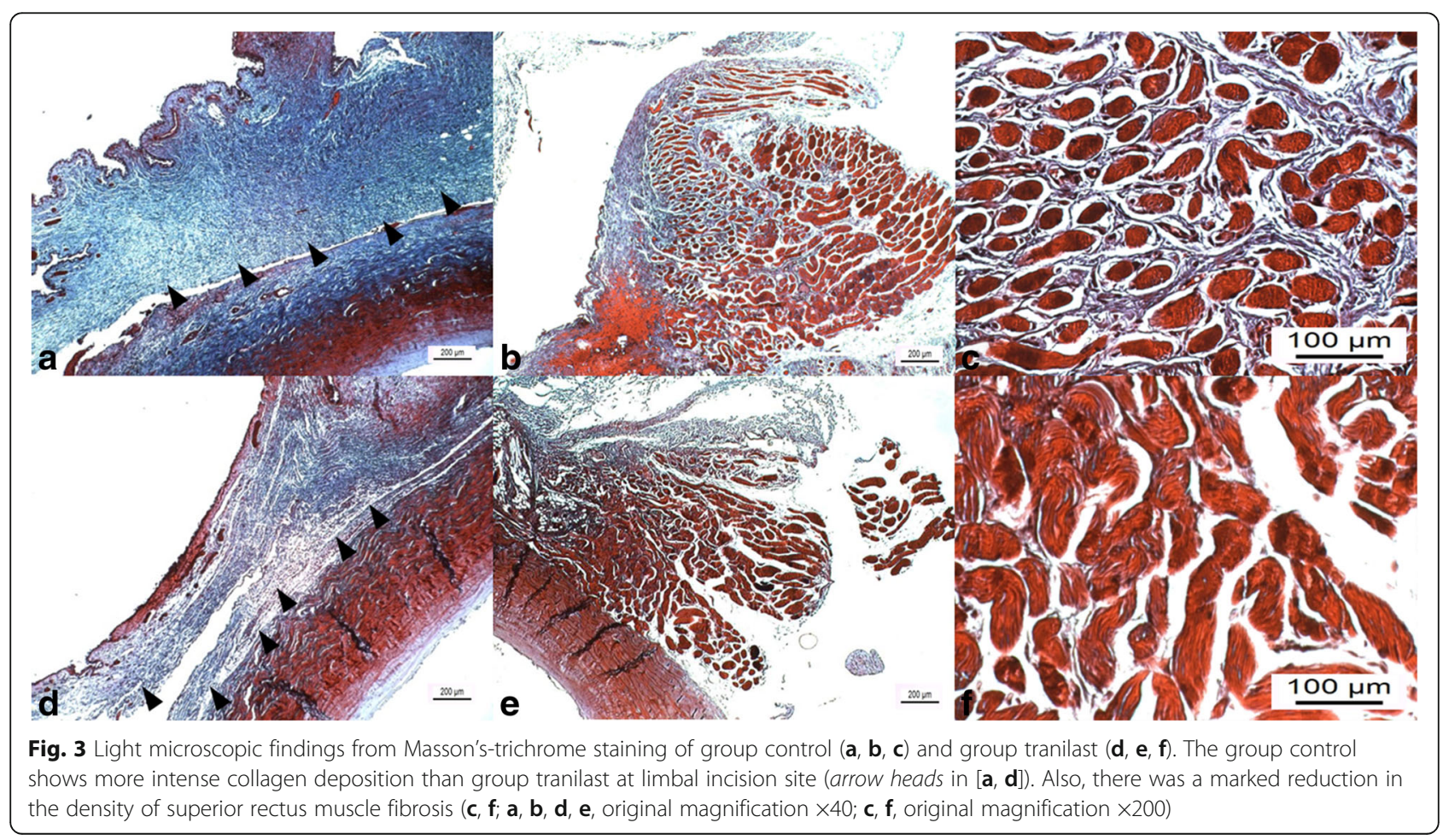


Table 3 Quantitative analysis of fibrosis through Masson's trichrome staining

\begin{tabular}{lcc}
\hline & Number of pixels $($ mean \pm SD) & \\
\hline Control & $133,798 \pm 60,855$ & $P<0.001^{*}$ \\
Tranilast & $54,011 \pm 26,873$ & \\
\hline
\end{tabular}

$S D$ standards deviation

*Mann-Whitney test

The TGF- $\beta$ superfamily consists of diversiform proteins that have pleiotropic function, including cell cycle control, chemotaxis, and wound healing $[29,30]$. The TGF- $\beta$ is well known as the crucial molecule in tissue organ fibrosis [31]. The TGF- $\beta$ signaling induces various mesenchymal precursor cells to myofibroblast transformation which characterized $\alpha$-smooth muscle actin expression and collagen secretion [32, 33]. TGF- $\beta 1,2$ and 3 are three isoforms exist in mammalian cells [34]. In human eye, it was previously reported that normal conjunctiva showed much weaker expression of TGF- $\beta$ family than fibrous conjunctiva tissue [35]. Moreover, TGF- $\beta 1$ is overexpressed in cultured fibroblasts from fibrous conjunctiva among three isoforms of TGF- $\beta$ [36]. Therefore, TGF- $\beta$, especially TGF- $\beta 1$, has been the treatment target to prevent the formation of postsurgical fibrosis and adhesions in strabismus surgery [37].

To our knowledge, there are no published reports on the histopathologic evaluation for the effect of tranilast eye drops after strabismus surgery. This study investigated the effects of tranilast eye drops on fibrosis and inflammation caused by extraocular muscle surgery in rabbits. Five weeks after operation, with $0.5 \%$ tranilast eye drops, the group tranilast demonstrated less gross adhesion, inflammation and fibrosis than the group control.

Those findings are comparable to previous studies reporting that a slow-release tranilast system reduced postoperative adhesions in strabismus surgery [22]. Hwang et al. wrapped the extraocular muscle with a sheet of polytetrafluoroethylene/polylactide-co-glycolide laminate with tranilast, reducing adhesion during a delayed adjustment procedure [22]. This system is highly effective, as it directly and consistently releases the active agent. However, a direct slow-release system requires an additional complicated surgical procedure and has the problem of remained foreign body in surgical site with the case of standard strabismus surgery. We therefore used more simple postoperative management and found that tranilast eye drops were comparable to a direct release system in terms of postoperative adhesion and fibrosis.

Tranilast eye drops may decrease surgical site adhesion and fibrosis via anti-inflammatory and anti-fibrotic action. Tranilast eye drops showed favorable antiinflammatory action as a cytokine modifier. It suppress the release of interleukin- 2 and interleukin- $1 \beta$ from monocytes and macrophages, which are key cytokines that initiate inflammation [11]. Furthermore, tranilast

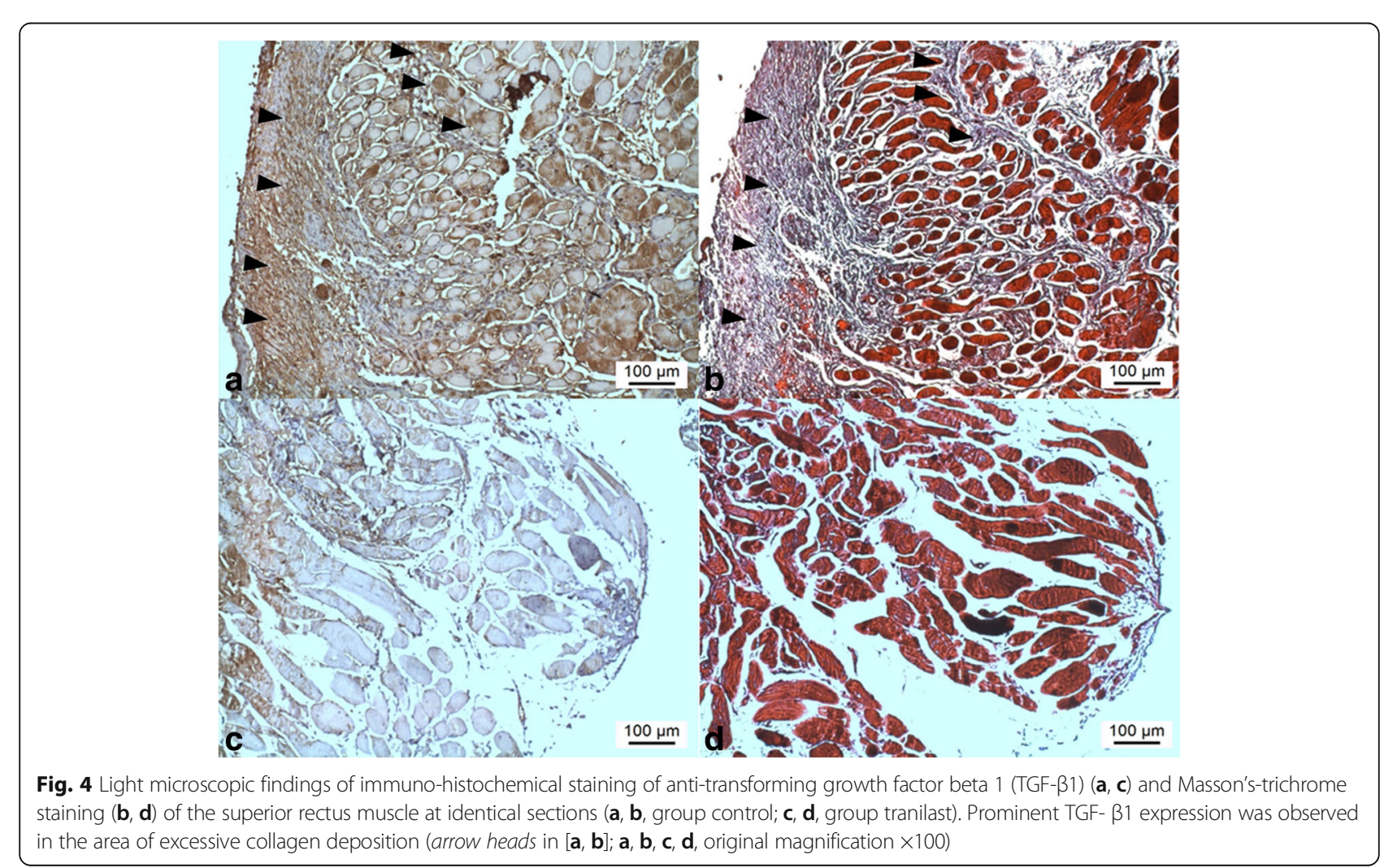


inhibits the progression of inflammation; it inhibits chemotaxis by suppressing the expression of vascular cell adhesion protein-1 and intercellular adhesion molecule 1 [38-40]. Additionally, tranilast has inhibitory effect of collagen deposition by inhibiting fibroblast proliferation [41] and limiting TGF- $\beta$ induced fibrosis and excessive formation of extracellular matrix inhibiting expression of TGF- $\beta 1$ [42, 43]. This effect could be obtained even by application of eye drops and was confirmed using Masson's-trichrome and IHC staining in the present study (Figs. 3 and 4).

The present study has some limitations. Surgical outcomes were evaluated at only one point, 5 weeks after surgery, to ensure completion of the proliferative phase, which includes collagen synthesis and adhesion formation [44]. This is suitable for evaluating fibrosis and surgical site adhesion, but earlier postoperative evaluation needs to clarify the role of tranilast in the acute inflammatory and proliferative phases of inflammation. In addition, it is necessary to investigate the effect of other anti-inflammatory and anti-fibrotic therapeutic agents, such as nonsteroidal anti-inflammatory drugs and steroids eye drops, compared to tranilast eye drops.

\section{Conclusions}

In conclusion, 5-week instillation of $0.5 \%$ tranilast eye drops is a simple and effective method for the prevention of post-operative adhesion and fibrosis after strabismus. This is the first experimental study to evaluate the effect of tranilast eye drops as a treatment for postoperative adhesion after strabismus surgery, through the downregulation of inflammation and fibrosis.

\section{Abbreviations}

H \& E: Hematoxylin \& eosin; IHC: Immunohistochemical; SRM: Superior rectus muscle; TGF- $\beta 1$ : Transforming growth factor beta 1

\section{Acknowledgements}

None.

\section{Funding}

None.

\section{Availability of data and materials}

All data will be made available upon request.

\section{Authors' contributions}

SUC 1st author, study design, conduct of study, data collection, analysis and interpretation of data, make out draft. KWK analysis and interpretation of data, make out draft, review. NJM study design, conduct of study, data collection, analysis and interpretation of data, make out draft, review, manuscript approval. All authors read and approved the final manuscript.

\section{Competing interests}

The authors declare that they have no competing interests.

\section{Consent for publication}

All authors gave consent to publish the manuscript. Also, this study did not include human participants.

\section{Ethics approval and consent to participate}

All experiments were conducted in accordance with the ARVO Statement for the Use of Animals in Ophthalmic and Vision Research. And, study protocol was approved by Chung-Ang university institutional animal care and use committee (No. 14-0043).

Received: 18 May 2016 Accepted: 9 September 2016

Published online: 21 September 2016

\section{References}

1. Mora JS, Sprunger DT, Helveston EM, Evan AP. Intraoperative sponge 5-fluorouracil to reduce postoperative scarring in strabismus surgery. J AAPOS. 1997:1:92-7.

2. Ozkan SB, Kir E, Culhaci N, Dayanir V. The effect of Seprafilm on adhesions in strabismus surgery-an experimental study. J AAPOS. 2004:8:46-9.

3. Solomon A, Espana EM, Tseng SC. Amniotic membrane transplantation for reconstruction of the conjunctival fornices. Ophthalmology. 2003:110:93-100.

4. Sheha $H$, Casas $V$, Hayashida $Y$. The use of amniotic membrane in reducing adhesions after strabismus surgery. J AAPOS. 2009:13:99-101.

5. Fulga V, Koren R, Ezov N, Gal R, Nimrod A, Savir H. Sodium hyaluronate as a tool in strabismus surgery in rabbits. Ophthalmic Surg Lasers. 1996;27:228-33

6. Brooks SE, Ribeiro GB, Archer SM, Elner VM, Del Monte MA. Fat adherence syndrome treated with intraoperative mitomycin-C: a rabbit model. J Pediatr Ophthalmol Strabismus. 1996:33:21-7.

7. Cruz OA. Evaluation of mitomycin to limit postoperative adhesions in strabismus surgery. J Pediatr Ophthalmol Strabismus. 1996;33:89-92.

8. Sondhi N, Ellis FD, Hamed LM, Helveston EM. Evaluation of an absorbable muscle sleeve to limit postoperative adhesions in strabismus surgery. Ophthalmic Surg. 1987;18:441-3.

9. Elsas FJ, Gowda DC, Urry DW. Synthetic polypeptide sleeve for strabismus surgery. J Pediatr Ophthalmol Strabismus. 1992;29:284-6.

10. de Carvalho LE, Alves MR, da Silva MA, Gaal Vadas MF. Experimental strabismus surgery using triamcinolone: outcomes and effects on inflammatory response. Arq Bras Oftalmol. 2007;70:209-15.

11. Suzawa H, Kikuchi S, Ichikawa K, Koda A. Inhibitory action of tranilast, an anti-allergic drug, on the release of cytokines and PGE2 from human monocytes-macrophages. Jpn J Pharmacol. 1992;60:85-90.

12. Koda A, Nagai $H$, Watanabe $S$, Yanagihara $Y$, Sakamoto K. Inhibition of hypersensitivity reactions by a new drug, N(3',4'-dimethoxycinnamoyl) anthranilic acid (N-5'). J Allergy Clin Immunol. 1976;57:396-407.

13. Fukuyama J, Miyazawa K, Hamano S, Ujiie A. Inhibitory effects of tranilast on proliferation, migration, and collagen synthesis of human vascular smooth muscle cells. Can J Physiol Pharmacol. 1996;74:80-4.

14. Isaji M, Miyata H, Ajisawa Y, Takehana Y, Yoshimura N. Tranilast inhibits the proliferation, chemotaxis and tube formation of human microvascular endothelial cells in vitro and angiogenesis in vivo. Br J Pharmacol. 1997:122:1061-6.

15. Ochiai H, Ochiai Y, Chihara E. Tranilast inhibits TGF- A1 secretion without affecting its mRNA levels in conjunctival cells. Kobe J Med Sci. 2001;47:203-9.

16. Yasukawa $T$, Kimura H, Dong J, Tabata Y, Miyamoto H, Honda Y, Ogura Y. Effect of tranilast on proliferation, collagen gel contraction, and transforming growth factor beta secretion of retinal pigment epithelial cells and fibroblasts. Ophthalmic Res. 2002:34:206-12.

17. Maita E, Sato M, Yamaki K. Effect of tranilast on matrix metalloproteinase-1 secretion from human gingival fibroblasts in vitro. J Periodontol. 2004;75:1054-60.

18. Oi W, Chen X, Twigg S, Polhill TS, Gilbert RE, Pollock CA. Tranilast attenuates connective tissue growth factor-induced extracellular matrix accumulation in renal cells. Kidney Int. 2006:69:989-95.

19. Tsuji A, Kawai K, Fan H, Nakagawa Y, Suzuki T. Case in which tranilast ophthalmic solution was thought to be effective for the prevention of symblepharon and recurrence after pterygium surgery. Tokai J Exp Clin Med. 2011;36:120-3.

20. Sakai T, Okamoto S, Iwaki Y. [The effect of tranilast on subepithelial corneal opacity after excimer laser keratectomy]. Nihon Ganka Gakkai Zasshi. 1997:101:783-7

21. Furukawa H, Nakayasu K, Gotoh T, Watanabe Y, Takano T, Ishikawa T, Kanai A. Effect of topical tranilast and corticosteroids on subepithelial haze after photorefractive keratectomy in rabbits. J Refract Surg. 1997;13 Suppl 5:457-8. 
22. Lee MJ, Jin SE, Kim CK, Choung HK, Jeoung JW, Kim HJ, Choe G, Hwang JM. Slow-releasing tranilast in polytetrafluoroethylene/polylactide-co-glycolide laminate delays adjustment after strabismus surgery in rabbit model. Invest Ophthalmol Vis Sci. 2007:48:699-704.

23. Lee JE, Han HJ, Lee JS, Oum BS. Effect of tranilast on the proliferation of human corneal keratocytes in vitro. J Korean Ophthalmol Soc. 2005;46:510-20.

24. Connor KM, Krah NM, Dennison RJ, Aderman CM, Chen J, Guerin KI, Sapieha P, Stahl A, Willett KL, Smith LE. Quantification of oxygen-induced retinopathy in the mouse: a model of vessel loss, vessel regrowth and pathological angiogenesis. Nat Protoc. 2009:4:1565-73.

25. Shokida MF. Use of a silicone sheet for delayed adjustable strabismus surgery. Ophthalmic Surg. 1993;24:486-8.

26. Hwang JM, Chang BL. Use of physical barriers for delayed adjustable strabismus surgery: the effect of interceed and polyglactin 910 mesh. Br J Ophthalmol. 1996;80:759-62.

27. Dougherty PJ, Hardten DR, Lindstrom RL. Corneoscleral melt after pterygium surgery using a single intraoperative application of mitomycin-C. Cornea. 1996;15:537-40.

28. Choi HY, Lee JH, Lee JE, Jung JH. Effect of bevacizumab on strabismus surgery in rabbits. Invest Ophthalmol Vis Sci. 2010;51:4585-8.

29. McCartney-Francis NL, Frazier-Jessen M, Wahl SM. TGF-beta: a balancing act. Int Rev Immunol. 1998:16:553-80.

30. Massague J. TGF-beta signal transduction. Annu Rev Biochem. 1998:67:753-91.

31. LeRoy EC, Trojanowska MI, Smith EA. Cytokines and human fibrosis. Eur Cytokine Netw. 1990;1:215-9.

32. Leask A, Abraham DJ. TGF-beta signaling and the fibrotic response. FASEB J. 2004;18:816-27.

33. Hinz B, Phan SH, Thannickal VJ, Prunotto M, Desmouliere A, Varga J, De Wever O, Mareel M, Gabbiani G. Recent developments in myofibroblast biology: paradigms for connective tissue remodeling. Am J Pathol. 2012;180:1340-55.

34. Roberts AB, Sporn MB. Physiological actions and clinical applications of transforming growth factor-beta (TGF-beta). Growth Factors. 1993;8:1-9.

35. Kria L, Ohira A, Amemiya T. Immunohistochemical localization of basic fibroblast growth factor, platelet derived growth factor, transforming growth factor-beta and tumor necrosis factor-alpha in the pterygium. Acta Histochem. 1996;98:195-201.

36. Kria L, Ohira A, Amemiya T. Growth factors in cultured pterygium fibroblasts: immunohistochemical and ELISA analysis. Graefes Arch Clin Exp Ophthalmol. 1998;236:702-8.

37. Jung Kl, Choi JS, Kim HK, Shin SY. Effects of an anti-transforming growth factor-beta agent (pirfenidone) on strabismus surgery in rabbits. Curr Eye Res. 2012;37:770-6.

38. Spiecker M, Lorenz I, Marx N, Darius H. Tranilast inhibits cytokine-induced nuclear factor kappaB activation in vascular endothelial cells. Mol Pharmacol. 2002;62:856-63.

39. Adachi T, Fukuda K, Kondo Y, Nishida T. Inhibition by tranilast of the cytokine-induced expression of chemokines and the adhesion molecule VCAM-1 in human corneal fibroblasts. Invest Ophthalmol Vis Sci. 2010;51:3954-60

40. Mizuno K, Okamoto H, Horio T. Inhibitory influences of tranilast on multinucleated giant cell formation from monocytes by supernatant of concanavalin A-stimulated mononuclear cells. J Dermatol Sci. 2000:24:166-70

41. Isaji $\mathrm{M}$, Nakajoh $\mathrm{M}$, Naito J. Selective inhibition of collagen accumulation by $\mathrm{N}$-(3,4-dimethoxycinnamoyl)anthranilic acid ( $\left.\mathrm{N}-5^{5}\right)$ in granulation tissue. Biochem Pharmacol. 1987;36:469-74.

42. Suzawa $\mathrm{H}$, Kikuchi S, Arai N, Koda A. The mechanism involved in the inhibitory action of tranilast on collagen biosynthesis of keloid fibroblasts. Jpn J Pharmacol. 1992:60:91-6.

43. Isaji M, Aruga N, Naito J, Miyata H. Inhibition by tranilast of collagen accumulation in hypersensitive granulomatous inflammation in vivo and of morphological changes and functions of fibroblasts in vitro. Life Sci. 1994:55:287-92

44. Velnar T, Bailey T, Smrkolj V. The wound healing process: an overview of the cellular and molecular mechanisms. J Int Med Res. 2009;37:1528-42.

\section{Submit your next manuscript to BioMed Central and we will help you at every step:}

- We accept pre-submission inquiries

- Our selector tool helps you to find the most relevant journal

- We provide round the clock customer support

- Convenient online submission

- Thorough peer review

- Inclusion in PubMed and all major indexing services

- Maximum visibility for your research

Submit your manuscript at www.biomedcentral.com/submit
Biomed Central 